\title{
Abdelmalek Sayad no Brasil: os Imigrantes Internacionais como um caso limite de agentes sociais forçados à reconversão ${ }^{1}$
}

Afrânio Garcia Jr²

Resumo: O objetivo deste texto é reconstruir o contexto e o alcance de duas missões realizadas por Abdelmalek Sayad no Brasil no início da década de 1990. Para tanto, o autor faz uma análise da trajetória intelectual do sociólogo argelino inspirada na "caixa de ferramentas" de Pierre Bourdieu, destacando suas filiações teórico-conceituais e seu interesse pelo tema da imigração. $\mathrm{O}$ artigo se concentra nos cursos e nas pesquisas de campo em conjunto objetivando os diálogos que Sayad estabeleceu com pesquisadores e instituições brasileiras nos anos 9o, última década de sua carreira acadêmica.

Palavras-chave: imigração; circulação internacional de intelectuais; Abdelmalek Sayad.

Abdelmalek Sayad in Brasil: international migrants as a borderline case of social agents forced to reconversion

Abstract: The purpose of this paper is to reconstruct the context and scope of two research missions carried out by Abdelmalek Sayad in Brazil in the early 1990 s.

\footnotetext{
Artigo traduzido do original em francês por Alexsandro Elias Arbarotti. Revisão técnica de Rodrigo Constante Martins.

2 École des Hautes Études en Sciences Sociales de Paris (EHESS) / Centre Européen de Sociologie et de Science Politique de Paris (CESSP) - Paris - França - afranio-raul.garcia@ehess.fr
} 
For this purpose, the author analyzes the intellectual trajectory of the Algerian sociologist inspired by "toolbox" of Pierre Bourdieu's, highlighting his theoretical-conceptual affiliations and his interest in the subject of immigration. The article concentrates on courses and field research aiming at dialogues that Sayad established with researchers and Brazilian institutions in the 1990s, the last decade of his academic career.

Keywords: immigration; international circulation of intellectuals; Abdelmalek Sayad.

\section{Introduç̃̃o}

O objetivo deste texto é reconstruir o contexto e o alcance de duas missões realizadas por Abdelmalek Sayad no Brasil no início da década de 1990. Entretanto, é impossível, para mim, contar essas viagens sem objetivar previamente as memórias e emoções despertadas por este exercício. Primeiro, a possibilidade de expor em Argel a primeira versão deste artigo me proporcionou uma grande alegria, aquela de estar entre os amigos, os antigos colaboradores e os jovens pesquisadores levando adiante os questionamentos levantados por Pierre Bourdieu e Abdelmalek Sayad nos anos 1950-1960. Mas este sentimento estava perpassado por um grande arrependimento, ligado à sua "dupla ausência", título do livro de Sayad depois do seu falecimento, que havia sido sugerido por Bourdieu, expressão percebida por Rebecca Sayad como um presságio, após a morte do sociólogo francês em 2002. ${ }^{3}$

Por outro lado, para um acadêmico brasileiro da minha geração, nascido pouco após o fim da Segunda Guerra Mundial, a referência à Argélia evoca "companheiros de rota" no cenário internacional, de próximos distantes, pois longo e árduo é o caminho daqueles que se engajaram em direção à via da construção nacional emancipada de toda tutela. A Argélia fora a terra de recepção de políticos brasileiros de esquerda, condenados ao exílio pelo golpe militar de 1964, notadamente Miguel Arraes, governador do Estado de Pernambuco, que assegurou as condições que permitiram as primeiras negociações coletivas de trabalhadores agrícolas da cana-de-açúcar, conduzindo a contratos coletivos de trabalho favoráveis aos assalariados, descendentes de escravos. Esta produção de direitos iguais aos descendentes dos Senhores e aos descendentes de escravos nunca foi perdoada pelas elites tradicionais, razão pela qual ele fora preso dentro do palácio onde exercia seu mandato. Argel figurou, portanto,

3 O livro de Sayad, que contou com prefácio de Pierre Bourdieu, foi publicado com o título La double absence: des illuisions de l'émigré aux souffrances de l'immigré (Paris: Éditions du Seuil, 1999). 
entre os importantes lugares do exílio político e intelectual brasileiro durante a ditadura (1964-85). Em setembro de 1969, no momento onde a tortura tornou-se moeda corrente para tentar neutralizar os adversários, é em Argel que pousou um avião conduzindo quinze prisioneiros libertos graças ao sequestro do Embaixador americano no Rio de Janeiro. Durante a década de 6o, quando a guerra fria estava em seu auge, a curiosidade sobre a experiência argelina estava tão forte que as lutas pela independência não poderiam ser percebidas como uma ação de militares "submissos às ordens dos Soviéticos" e nem tributários da hegemonia norte-americana em rápida progressão. $\mathrm{O}$ que foi chamado em seguida de "Terceiro mundismo" foi, inicialmente, a busca por caminhos originais de construção de espaços políticos diante da pressão de dois polos da Guerra Fria. O famoso livro do antropólogo norte-americano Eric Wolf - Guerras camponesas do Século XX (1974) - estudando seis casos históricos paradigmáticos - México (1910), Rússia (1917), China (1947), Vietnam (1954), Argélia (1954) e Cuba (1958) - é um bom revelador deste interesse em compreender as evoluções históricas que não pareciam redutíveis aos modelos concebidos para explicar a passagem dos Impérios à nações, no espaço europeu ou na origem de novas nações na América do Norte (Estados Unidos da América e Canadá). A descolonização de sociedades menos urbanizadas e industrializadas era certamente um processo dificilmente equiparável à simples reprodução das transformações históricas de um dos antigos "corações da civilização", ou, dentro de um registro desencantado, de uma das grandes potências em competição pela hegemonia mundial. Edificados em paradigmas, os modelos construídos para explicar as mudanças históricas dos países europeus colocam muitas vezes entraves ao estudo e à demonstração das invariáveis dos processos de construção nacional. ${ }^{4}$

Pierre Bourdieu e Abdelmalek Sayad foram, de início e antes de tudo, para toda uma equipe de jovens antropólogos do Museu Nacional do Rio de Janeiro,

4 Gérard Noiriel renovou esta problemática da afirmação nacional estudando a diferença entre os processos políticos e culturais na origem das primeiras nações europeias, especificamente a França. Ele especifica que ao lado da afirmação do corpo político constituído pelo conjunto de cidadãos, agora percebidos como o "povo soberano", a constituição nacional pressupôs, antes de tudo, a imposição de referências culturais comuns, susceptíveis de distinguir uma população determinada (língua, literatura, música, artes, festas emblemáticas etc.). A generalização precipitada, atribuindo a todas as nações a ordem dos acontecimentos na França, é severamente criticada: "o universalismo é um particularismo que se ignora" (p. 17). Na França, o romantismo moldou o caráter singular da ordem cultural, processo tardio, que havia precedido a construção do Estado moderno em outros países europeus, como demonstrou Anne-Marie Thiesse (ver Noiriel, 2007; 1992; Thiesse, 2001). Estes autores observam que a evolução da cena internacional, tanto sobre estes aspectos políticos como culturais, é uma dimensão central da institucionalização de todo Estado nação. 
autores de pesquisas e de monografias exemplares, como Travail et travailleurs en Algérie e Le Déracinement, permitindo objetivar a verdadeira mutação das configurações sociais e dos sistemas cognitivos impostos às sociedades camponesas, em nome da passagem para a "economia de mercado". A colonização moderna, sobretudo a implementada no Século XIX, implica, como as precedentes, a transferência de riquezas para a metrópole, mas também a reestruturação das atividades produtivas da colônia sob a forma de empresas inscritas nos mercados nacionais e internacionais; é o conjunto da vida social e cultural dos "povos primitivos", ou das "sociedades camponesas", que é atingida deste modo. Estes livros demonstram uma afirmação teórica de consequências de grande alcance sobre as ligações entre as mudanças culturais e mudanças sociais. $\mathrm{O}$ simples fato de estarem objetivamente submetidos aos imperativos da economia de mercado não dota os antigos camponeses com as ferramentas mentais capazes de fornecer-lhes condutas adaptadas à sua nova condição. A leitura cuidadosa destes livros possibilitou a aquisição de um conjunto de questões e de instrumentos de pesquisa para buscar compreender as profundas transformações nas plantações açucareiras do Nordeste, após a emergência de um vigoroso movimento social baseado no nascimento do sindicalismo dos trabalhadores agrícolas, responsáveis pela extensão dos direitos do trabalho e proteção social no campo. ${ }^{5}$

Com este avanço de camadas de camponeses destituídos no Nordeste, em busca de um pedaço de terra onde fixar residência e de ter terras aráveis para cultivar ao menos uma parte da sua alimentação doméstica, as elites agrárias tradicionais retaliaram pela eliminação de todas estas as vantagens concedidas às famílias dos trabalhadores agrícolas, que viviam no interior das grandes propriedades e eram empregados nas culturas de exportação (cana-de-açúcar, café, algodão, cacau etc.), em primeiro lugar, a moradia acompanhada de acesso livre à água, à madeira para cozinhar e à uma pequena horta. Tal como demonstrou Lygia Sigaud (1979, 1980), as representações dos trabalhadores agrícolas na década de 70 associavam ao passado nas plantações a imagem de uma "era de abundância”, oposta ao presente de miséria, onde a fome rondava durante os períodos de escassez de alimentos autoproduzidos. As mobilizações sociais sendo reprimidas depois do golpe de estado de 1964 passam a ser as estratégias de reconversão dos grandes proprietários favorecidas pela ação do Estado, imponto a partida em massa dos trabalhadores agrícolas para as cidades, completamente privados de recursos materiais e cognitivos para se incorporarem de

5 Para a relação entre as pesquisas sobre o Nordeste e as obras sobre a Argélia da década de 6o, ver Garcia Jr., 2003. 
uma maneira bem sucedida ao universo social urbano marcado pela expansão do assalariamento. $O$ corpo dos oficiais militares, em um caso conduzindo uma guerra para perpetuar a dominação colonial no Magrebe, e no outro reprimindo com violência para perpetuar a dominação sobre os herdeiros de linhagens fundadas pelos senhores de escravos, era a principal garantia das transformações sociais que causavam a deterioração das condições de vida do campesinato e a aniquilação da eficácia dos modelos culturais pré-existentes. No Brasil, a monetarização de todas as interações sociais estava correlacionada com a pauperização absoluta e relativa do contingente de descendentes de escravos. Ainda mais doloroso, o sistema de representações baseado na reciprocidade entre a proteção dos senhores e a fidelidade dos dependentes foi abaixo. $\mathrm{O}$ mundo moderno era acompanhado de um aumento de oportunidades para os descendentes dos senhores e uma diminuição de oportunidades de garantir a sobrevivência, percebidas como perdas sem qualquer contrapartida, para as antigas camadas de camponeses e trabalhadores agrícolas. As desigualdades de todos os gêneros só aumentaram depois disso, até uma época muito recente (sob a presidência de Lula uma política de transferência de renda foi implementada), alguns podendo implementar toda uma gama de estratégias de reconversão e outros cada vez mais submissos a todas as urgências, sem os meios de enfrentá-las. Não é surpreendente que, no Brasil, como em muitos países da América do Sul, o crescimento econômico, mesmo acompanhado de maiores rendimentos agrícolas e da produtividade, não surge como sinônimo de melhores condições de vida para a maioria da população e certamente não do campesinato; seguramente, a percepção deste duplo processo esteve no início dos debates sobre o conceito de "desenvolvimento", introduzindo outras dimensões do que somente a expansão da renda per capita, ou mesmo dos postos de trabalhos criados, para avaliar o alcance das evoluções econômicas. A simples leitura dos trabalhos sobre o espaço argelino não fornecia, obviamente, o modelo pronto das transformações em curso no Nordeste do Brasil, mas sugeria questões teóricas para examinar empiricamente, pistas para a compreensão dos processos de transformação social, técnicas de objetivação para conduzir nossas próprias investigações no Nordeste e elaborar modelos explicativos permitindo ampliar o horizonte dos encadeamentos teóricos de partida.

Estes trabalhos de investigação no Nordeste deram origem a inúmeras monografias, sendo que algumas foram discutidas no Centro de Sociologia Europeia (CSE) desde 1976, dando origem a várias publicações, inclusive na revista 
Actes de la recherche en sciences sociales. ${ }^{6}$ A intensificação da cooperação científica entre o Museu Nacional e o CSE nos anos 80 permitiu as duas estadias de Sayad no Brasil, em 1990 e em 1994. São as aulas que ele ministrou nestas ocasiões, as incursões em campo realizadas juntamente com diferentes pesquisadores (no Nordeste, no Rio e em São Paulo), os artigos e as entrevistas publicadas após sua estada que serão o tema da continuidade da nossa comunicação. Abdelmalek Sayad tornou-se atualmente um autor bem conhecido no Brasil: o livro "Imigração ou os paradoxos da alteridade" (1998) foi publicado pela editora da Universidade de São Paulo (USP), a mais importante do gênero; os artigos "Uma pobreza éxótica': a migração argelina na França" (1991) e "O retorno elemento constitutivo da condição do imigrante" (2000) foram editados pela Revista Brasileira de Ciências Sociais da Associação Nacional de Pós-Graduação e Pesquisa em Ciências Sociais (ANPOCS) e pela Travessias: Revista do Migrante, publicada pelo Centro Pastoral do Migrante, e "La Double absence" deve ser traduzido em breve. É preciso observar que de acordo com o trabalho estatístico realizado sobre os autores citados nas teses de doutorado em ciências sociais entre 1990-1994 (Cunha Mello, 1999), Pierre Bourdieu aparece como o autor mais referenciado, ultrapassando até mesmo a tríade clássica Karl Marx, Max Weber e Emile Durkheim. No entanto, Sayad é tido como um dos mais próximos colaboradores de Bourdieu, além disso, tratando de dois temas fundamentais para pensar o Brasil: o desenraizamento das populações rurais e o alcance das migrações de longa duração e distância. Somente alguns números para dar uma ideia da extensão das mutações no Brasil relacionados às migrações ao longo do Século XX: em 1940, apenas 30\% da população habitava em áreas urbanas, contra 70\% em 1980. A morfologia social se inverteu ao longo de quatro décadas, que viram também o país agrícola se tornar industrializado e dotado de meios modernos de comunicação. $O$ desenraizamento massivo, sob o pano de fundo da escravidão, desde o Século XVI, é certamente a experiência comum de uma considerável parcela de brasileiros. Quem poderia surpreender-se do eco profundo da problemática tratada no último capítulo do Desenraizamento: quais seriam as condições sociais, econômicas e culturais para pensar o futuro coletivo e o orientar na direção precisa?7 Seria necessário lembrar que as transformações atuais no campo de poder internacional, chamado um pou-

6 [N.T. Revista francesa fundada por Bourdieu, em 1975, junto com um grupo de estudiosos afiliados ao Centro de Sociologia Europeia].

7 Garcia-Parpet retoma os escritos de Pierre Bourdieu na década de 1950 e 1960 e tentar demonstrar que a análise focalizada sobre a economia visa também a discutir as condições econômicas e sociais da elaboração do projeto político concernente ao futuro da nação argelina. (Garcia-Parpet, 2005) 
co rápido "mundialização", reforçam o interesse científico pelos trabalhos de Pierre Boudieu e Abdelmalek Sayad desde a fase argelina? As análises tratando sobre a Argélia, conduzidas no início em comum, e aquelas posteriores sobre a França, feitas em paralelo, mas convergentes, não são de formidáveis "descrições densas" (thick descriptions) no senso empregado por Clifford Geertz para monografias exemplares?

\section{Abdelmalek Sayad no Brasil}

Sayad pôde ir ao Brasil graças a missões financiadas dentro do acordo de cooperação científica entre a França e o Brasil, conhecida como CAPES-COFECUB, ${ }^{8}$ que permitiu projetos entre o Centro de Sociologia da Educação e da Cultura (CSEC), dirigido por Monique de Saint-Martin e Jean-Claude Combessie e o Programa de Pós-graduação em Antropologia Social do Museu Nacional (PPGAS/ MN). Ele permaneceu no Brasil de 31 de agosto a 12 de outubro de 1990, pela primeira vez, e de setembro a outubro de 1994, na última vez. Sofrendo de graves doenças, que restringia seus movimentos, ele figurava entre os amadores dos prazeres da mesa e ainda mais se partilhada com seus amigos; nós ficamos felizes em constatar no Rio que a caipirinha bem doce e o feijão preto misturado com arroz - comida de base dos brasileiros - não estavam sujeitos às mesmas interdições e restrições que os cereais consumidos na França e na Argélia. Rapidamente, ele percebeu que poderia locomover-se facilmente sem nenhuma preocupação alimentar, contrariando as previsões pessimistas de todos os médicos consultados na França e no Rio. Este detalhe teve sua importância para fazê-lo sentir-se em casa no Brasil, uma espécie de lugar geométrico entre a Argélia e a França para se consumir sem moderação.

A particularidade do momento histórico não é, sem dúvida, estranha à experiência vivida da viagem, como me relataram várias testemunhas na França e outras tantas em Argel. No cenário internacional, a primeira Guerra do Golfo acabava de acontecer e ele pôde constatar como os brasileiros ficaram chocados com as imagens dos bombardeamentos e das explosões de mísseis, atingindo principalmente a população civil. A barbárie da guerra fazia par com a sofisticação científica e tecnológica e era difícil identificar-se com os pilotos de avião ou com os comandantes militares dos bombardeios, mas o questionamento sobre o cotidiano das populações atingidas pelas explosões tocava os espíritos dos espectadores de televisão aterrorizados... Por outro lado, a queda do muro de

8 [N.T. Respectivamente Coordenação de Aperfeiçoamento de Pessoal de Nível Superior e Comitê Francês de Avaliação da Cooperação Universitária com o Brasil]. 
Berlin, em 1989, despertou as esperanças na evolução do cenário internacional e o discurso midiático sobre a "globalização" (versão americana), ou a "mundialização" (versão francesa), não havia ainda revelado as suas mil e uma facetas de imposição de preceitos neoliberais, facilitada por uma política internacional do governo estadunidense que não hesitou em romper os compromissos em vigor desde a criação da Organização das Nações Unidas (ONU).

Também no Brasil, as esperanças pela democratização da vida nacional, tanto no plano dos direitos civis quanto no plano econômico e social, assegurando condições de vida digna para a maioria da população vivendo na miséria e sem acesso aos benefícios do forte crescimento econômico entre 1940-1980, pareciam frustradas por todos os lados. O primeiro presidente civil, Tancredo Neves, eleito para pôr fim ao regime dos generais, em seguida aos compromissos de todos os tipos para acabar com o regime de arbitrariedade, morreu no momento em que iria assumir suas funções; o vice-presidente havia constituído seu capital de notoriedade política a serviço da elite militar após 1964 e tinha mudado de lado no último momento ao sentir o vento mudar. O primeiro presidente em exercício no cargo depois da saída dos generais - José Sarney - não era oriundo de qualquer um dos muitos componentes da frente de oposição aos militares e nem mesmo originário dos antigos liberais. A constituição de 1988, votada durante seu mandato por uma Assembleia Constituinte, mesmo se garantisse o restabelecimento das liberdades civis e incorporasse inovações institucionais que carregam a marca das grandes mobilizações populares do período 1978 1985, guardam igualmente impresso um peso considerável das forças políticas tradicionais, que tiveram seu crescimento sob a presidência dos generais. Acima de tudo, as primeiras eleições gerais com voto direto para a presidência da República consagrou, no segundo turno, um jovem político - Fernando Collor de Mello -, originário das oligarquias do Nordeste e de uma família estabelecida entre as tradicionais elites açucareiras. A frente anti-Lula também espalhava o pânico entre as camadas ricas diante do avanço dos setores populares; um dirigente industrial de São Paulo, presidente da Federação patronal (FIESP), havia até mesmo acenado com a ameaça da partida massiva de empresários para o exterior se a vitória coubesse ao ex-sindicalista.

Período de corrupção sem precedentes, o mandato presidencial de Collor fora interrompido por um impeachment votado pelo Congresso Nacional, após mobilizações populares de grande amplitude. A inflação acelerou-se ao longo dos anos 80 e constituía outro obstáculo a toda tentativa de tornar transparente a gestão do Estado. A implementação do plano de estabilização monetária, em 1994, por F. H. Cardoso, como ministro da fazenda do presidente interino, 
garantiu-lhe a vitória contra Lula, ex-sindicalista que reagrupava novamente as forças populares e a frente de esquerda. A segunda viagem do casal Sayad aconteceu no momento em que o sociólogo, reconhecido internacionalmente, iria assumir a presidência, tendo feito a promessa de sanear as finanças do Estado, colocar definitivamente fim à hiperinflação e combater a pobreza extrema para criar a emergência de uma nova categoria de cidadãos, dotando, assim, de fundamentos sólidos a nova República. $\mathrm{O}$ mundo intelectual estando dividido à época como atualmente, entre os partidários de Cardoso e os de Lula; a segunda viagem de Sayad foi marcada por longas conversas sobre as possíveis evoluções do campo político brasileiro e seu impacto nas dinâmicas sociais. $\mathrm{O}$ vasto e preciso questionamento de Sayad sobre o mundo social brasileiro, mas também sobre o universo político e intelectual, contribuiu enormemente para mostrar as lacunas das explicações tidas como suficientes até então e a fomentar as interrogações sobre as bases das posturas intelectuais e políticas adotadas. Para Sayad, as sugestões tomavam geralmente a forma de dúvidas e de questões sobre as possibilidades não realizadas; nunca apresentavam-se como uma forma arrogante do conselho do especialista.

Sayad foi acolhido por um programa de doutorado em Antropologia Social, implantado em 1968 em um museu de história natural, o Museu Nacional do Rio de Janeiro, a mesma instituição implicada na expedição analisada em Tristes Trópicos (Lévi-Strauss, 1996), por ter servido de suporte à expedição dirigida por Claude Lévi-Strauss, em 1938, no Mato Grosso. Os cursos e seminários oferecidos pelo Programa de Pós-Graduação em Antropologia Social do Museu Nacional (PPGAS/ MN) foram destinados aos estudantes de mestrado e doutorado e utilizaram amplamente, desde o início, a literatura internacional em ciências sociais, incluindo publicações em inglês, francês e espanhol. A antropologia social parece ter desempenhado um papel muito importante na internacionalização das questões de pesquisa, obrigando a quebrar os compartimentos e fronteiras das questões limitadas pela hegemonia sem contraste do nacionalismo cultural das décadas de 1930-1960. De fato, a importância de um artigo ou de uma monografia em etnologia não está ligada à proximidade geográfica do objeto tratado em relação aos lugares estudados pelo aprendiz de pesquisador. O ponto central é a relevância científica dos questionamentos examinados e as ferramentas de pesquisa colocadas à disposição de todo novo pesquisador; a proximidade territorial entre os grupos sociais tem apenas um interesse secundário ou nulo. Este programa de mestrado (1968), seguido da implementação do doutorado (1977), pôde associar desde o início as discussões teóricas com o 
trabalho de campo, graças ao apoio da Fundação Ford9 e a cooperação científica firmada com a Universidade de Havard (GARCIA JR, 2009). Assim, já no seu surgimento, os estudantes matriculavam-se em projetos de pesquisa, voltados aos estudos dos grupos Gê do Brasil Central (parentesco e cosmologia), ou então sobre "o desenvolvimento regional comparado" das regiões Nordeste ou Centro-Oeste e Amazônia. Concretamente estudados neste contexto de transformações sociais na origem das intensas migrações, bem como do campo em direção às cidades, deslocamentos que implicavam percursos muito longos, como os do Nordeste em direção às metrópoles do Sudeste (Rio de Janeiro, São Paulo), ou, também, do campo, ou mesmo das cidades situadas próximas do litoral em direção à Amazônia e o Centro-Oeste (PALMEIRA; ALII, 1978). A estabilidade dos quadros de existência do campesinato brasileiro pressupunha, muitas vezes, vínculos de fidelidade e troca de favores com as elites tradicionais, que controlava os recursos fundiários e o poder local; os deslocamentos inscreveram-se desde longa data como tentativas familiares estratégicas de emancipação e autonomia. Toda a segunda metade do Século XX fora marcada pela intensificação das migrações em direção às cidades em vias de industrialização e em direção à fronteira agrícola na Amazônia.

Os antropólogos formados desde o fim dos anos 60 no PPGAS/MN gozaram de um duplo privilégio: eles tiveram acesso aos estudos de pós-graduação por meio do ensino público e gratuito; e, também, as pesquisas de campo constituíam um elemento indispensável da formação e foram financiadas integralmente. Nada parecido havia existido para as gerações anteriores; não é surpreendente que a profissão de antropólogo tenha conhecido uma expansão de efeitos nunca visto anteriormente. Em 1990, o PPGAS/MN desfrutava da reputação de ser o polo central da renovação da antropologia no Brasil e um dos centros de ensino e pesquisa responsáveis por novos ventos nas ciências sociais.

Os cursos propostos por Sayad em 1990 concentravam-se sobre três grandes eixos, repetidos, de forma geral, em 1994. Em primeiro lugar, foram examinadas "as condições sociais da imigração da Cabília para a França"; em seguida, foram estudadas "as perturbações relacionadas à guerra de independência" (Sayad recusava a denominação "guerra da Argélia"); para terminar por analisar "as três fases da imigração argelina na França", detalhando com sutileza as relações entre as diferentes gerações e as múltiplas configurações da nova sociedade resultante da migração para a Europa. Isto é, o estudo cuidadoso do percurso completo dos migrantes, desde a situação de partida até a situação de chegada, 
estendendo-se sobre os dilemas vividos pelas novas gerações, demonstrando claramente que se os indivíduos que se deslocam são os mesmos, as expectativas e as imagens aos quais eles são confrontados divergem completamente. $\mathrm{O}$ emigrante não existe se não para aqueles que o acolhem. Alguns reconhecem apenas sua transfiguração, o imigrante. $\mathrm{O}$ imigrante para os outros é classificado de acordo com os problemas da sociedade de acolhida (saúde, escolaridade, habitação, costumes alimentares, sexualidade etc.) que, às vezes, nem fazem sentido para o grupo de partida. $\mathrm{O}$ emigrante nunca é reduzido à imigrante, nem vice-versa; esta oposição entre dois universos sociais, entre dois sistemas de representação, manifesta-se em relação às práticas mais comuns observadas por uns e por outros, mas perpassa necessariamente o mundo subjetivo de todo migrante. A sociologia exigente de Abdelmalek Sayad nunca poderia sustentar um quadro estritamente interacionista: o que ocorre no ponto de partida continua a existir socialmente após a partida do ausente; as exigências do ponto de chegada possuem muito frequentemente origens bem anteriores aos fluxos migratórios. O deslocamento do indivíduo provoca a experiência de ser confrontado a condições de práticas banais e a expectativas completamente diferentes nos dois polos, assim frequentemente divergentes. $\mathrm{O}$ fato de cruzar fronteiras entre unidades territoriais autônomas é muito menos importante que esta experiência subjetiva e objetiva de ter que subsistir em duas configurações sociais dotadas de categorias de entendimento e de normas diversificadas. A capacidade de superar esta provação faz parte do questionário sociológico relevante e torna o migrante um indivíduo social em nada parecido com os outros. $O$ título e o subtítulo, De la Double absence: des illusions de lémigré aux souffrances de lémigré [da Dupla ausência: das ilusões do emigrado aos sofrimentos do emigrante], levam ao limite os obstáculos da afirmação do indivíduo, dando o pontapé inicial às análises das migrações e deixando a porta aberta ao tratamento intergeracional da linhagem constituída pelos imigrantes.

O imigrante é sempre confrontado a um universo simbólico que não o habita, uma vez que ele fora socializado inicialmente num outro universo social. Ele descobre às suas próprias custas e no sofrimento que ele não possui grande parte do universo simbólico necessário para uma inscrição bem sucedida na sociedade de acolhida (como a língua, os hábitos alimentares e vestuários, os modos de sociabilidade em vigor, as modalidades de patrimônio econômico valorizados etc.). Um investimento específico e novo é necessário se ele quiser inscrever-se no jogo de competição com chances de sucesso, muitas vezes com esforço dobrado para diminuir o impacto ou a eliminação de todos os comportamentos e marcas que significam estigmas nas sociedades de acolhimento (o 
sotaque, os hábitos corporais, os gostos esportivos etc.). A análise sociológica de Abdelmalek Sayad, sempre empiricamente fundamentada e ilustrada como uma extrema sensibilidade, ensinava, a nós do Museu Nacional, o que a mobilidade de longa distância significava, tratando-se ela de distância geográfica ou social. Para um imigrante, nada é natural, nada é evidente, todas as certezas ancestrais são recolocadas em questão, quer ele queira ou não. Objetivamente, ele é confrontado com os limites das suas convicções e hábitos de pensamento mais íntimos. A dúvida instala-se na ordem das coisas. Ele pode voltar, mas isto repercutirá sobre sua imagem junto aos seus próximos, a vergonha de si o espreitará de diferentes pontos de vista. Por isso, o argumento muito convincente empregado por Sayad, segundo o qual as migrações, bem analisadas, são formidáveis reveladores do mundo social e de sistemas de representações que lhes servem de sustentação. A miséria humana do desenraizamento, escutada atentamente, tornava-se uma lição sem equivalente da variação quase infinita do mundo social e dos significados que nós lhe atribuímos. A arrogância dos abastados, aqueles que estão sempre felizes com sua própria situação arbitrária, e que a afirmam constantemente sem consideração pelas situações dos outros, deleitando-se no etnocentrismo para falar como os antropólogos, repousa também no esquecimento de colocar para si mesmo as questões às quais todo imigrante é confrontado. Os abastados possuem um privilégio que os distinguem: eles podem afastar, colocar distância frente à questão da relevância de suas categorias de entendimento e das normas aos quais elas são associadas. Depois de Sayad, a sociologia das migrações tornou-se, assim, um capítulo central na sociologia dos modos de dominação. Sem sombra de dúvida, esta sociologia das migrações trata igualmente sobre as situações onde as estratégias de reprodução entram em pane, convocando os indivíduos a tentar sua reconversão; as migrações podem, por consequência, figurar como um caso limite de estudos das estratégias de reconversão, das condições de sua criação e da sua eficácia.

Além de todas estas considerações propriamente teóricas, os professores-pesquisadores e os doutorandos puderam apreciar a reconstrução de um longo processo de transformações históricas, relativas à colonização e à descolonização da Argélia, que poderia somente avançar explicando ao mesmo tempo a reflexão sobre as condições de conhecimento deste processo. A explicação das circunstâncias históricas desta viagem ajudará, talvez, a compreender que a fascinação do público por seus seminários não é uma razão suficiente para explicar porque Sayad envolveu-se completamente neste exercício. Felizmente, a gravação das suas intervenções em cassetes - que ainda esperam ser transcritas para uma publicação - permite constatar o conteúdo dedicado às memórias e 
o esforço de objetivar as situações históricas vividas e limitadas. Mais de uma vez, Sayad repetiu que o que ele tinha dito no Brasil nesta ocasião não seria dito nem na França e nem na Argélia. Como se o Brasil houvesse lhe proporcionado a ocasião de estar próximo e distante da Argélia e da França, permitindo ao emigrante e ao imigrante que ele era tentar explicitar, com a ajuda de modelos e de ferramentas de pensamento que ele tinha contribuído para a criação, os fundamentos sociais das escolhas que ele foi levado a fazer para orientar seu próprio itinerário.

De uma maneira bem concisa, este itinerário foi objeto de uma publicação na Revista Mana, editada no Museu Nacional, organizada por Federico Neiburg; eu tive a ocasião de voltar a ela, de uma forma ainda mais sumária, no seu texto introdutório para a revista Travessias. Mas eu não me desespero para encontrar os meios de explorar e estudar este material, que coloca em relação os resultados das pesquisas aos quais Sayad participou ou conduziu e a reflexão sobre sua relação ao objeto examinado. Sobretudo que se pode constatar como a descrição etnográfica das situações sociais estudadas desencadeou memórias e reflexões que permitiram a compreensão da perspectiva adotada para a construir, de precisar seu caráter arbitrário e de compará-la com outras narrativas contemporâneas. Esta revisão de situações vividas na urgência não tinha nada a ver com a complacência narcisista que chamamos regularmente de "memórias"; ela obrigava a imersão nos limites sociais do universo de partida, como do universo de chegada, mesmo se elas não foram apreendidas enquanto tais no momento da sua experiência subjetiva, e assumir que a análise é sempre um terceiro movimento, que pode ser feito de um modo aprofundado quando não estamos mais "imersos" no universo social que objetivamos. Por exemplo, num outro país de "desenraizados" como o Brasil, mesmo se as migrações não colocaram em jogo e em questão as fronteiras nacionais. Isto porque as migrações não eram somente muito longas; elas também forçavam ao confronto de universos sociais bem diferentes, de categorias de entendimento opostas sobre muitos dos aspectos cruciais para a existência cotidiana, mesmo se a língua fosse a mesma em todos os lugares, reforçando, por vezes, a percepção de uma falsa homogeneidade da cultura nacional. Em suma, a mobilidade implicava geralmente uma metamorfose social e reconversões em série. $\mathrm{O}$ migrante é o signo de um mundo em recomposição; a escuta da palavra do migrante é um recurso precioso para iluminar os contornos das situações atravessadas e para decifrar os conflitos sociais e as batalhas sobre o significado dos objetos percebidos. Nada está mais longe da postura sociológica exibida por Sayad que a pretensão de dispor de qualquer coisa como um modelo pronto e acabado da 
mudança social, seja ele limitado ao "terceiro mundo" ou aos "países subdesenvolvidos". Por isso, a sua formidável disposição de completar seus cursos com a discussão de pesquisas em curso no Brasil mediante idas a trabalhos de campo conjuntamente.

Ele estava interessado em participar de pesquisas sobre os cortadores de cana no Nordeste (coordenada por Moacir Palmeira) e visitar o foco das mobilizações operárias dos metalúrgicos no $\mathrm{ABC}^{10}$ (onde Lula iniciou sua militância), em 1990. Durante a segunda viagem, os trabalhos de campo concentraram-se nos bairros periféricos e muito pobres do Rio de Janeiro (Nova Iguaçu) e sobre o crescimento das favelas (Rocinha/ Morro Santa Marta). Cada trabalho de campo foi precedido por discussões sobre os ganhos da bibliografia disponível a este propósito e as aulas subsequentes permitiram precisar os pontos cegos e os novos objetos de pesquisa. Suas missões também permitiram a evolução das problemáticas estudadas até então no Museu Nacional.

\section{A constituição de novos objetos de pesquisa}

As estadias prolongadas no Brasil permitiram a Sayad medir a considerável amplitude das migrações no Brasil e que a vida cotidiana trazia traços dela de uma maneira ainda mais notável que na França. Certamente, o Brasil conheceu desde o fim do Século XIX, especialmente depois de 1870, uma entrada, de início, de imigrantes de origem europeia, seguida por contingentes de japoneses ou provenientes do Oriente Médio ou, ainda, da Europa Central. Este chamado à imigração fora ainda mais importante à medida que os debates a respeito da abolição da escravidão intensificavam-se, as pressões das grandes potências europeias aumentavam e as antigas elites agrárias, ou de exploração de jazidas de ouro e diamantes (sobretudo em Minas Gerais e Bahia) queriam dotar-se de uma nova fonte de mão de obra barata e promover "o branqueamento da raça". No entanto, este novo componente da população brasileira representou uma parcela crescente do total até a década de 1920, caindo na década de 1930 a porcentagens residuais no conjunto da dinâmica geral. ${ }^{11}$

A partir das décadas de 1930-40, um novo movimento migratório se desencadeava, ligado à expansão do mercado de trabalho industrial e à modernização

10 [N.T. A região do ABC é uma região industrial do Estado de São Paulo que faz parte da região metropolitana do município de São Paulo. A sigla refere-se aos municípios que formam a região: Santo André, São Bernardo e São Caetano].

11 Para os dados demográficos completos, ver les Cahiers du Brésil Contemporain, $\mathrm{n}^{\circ}$ 40, 2000, consagrados as séries estatísticas do Século XX, intitulado, "Brésil, le siècle des grandes transformations". 
dos serviços, fornecidos pela expansão e centralização do Estado Federal no Brasil, particularmente nos campos da saúde, da educação e do mercado cultural. ${ }^{12}$ É assim que a morfologia social encontrou-se invertida em menos de quatro décadas, como havíamos já mencionado anteriormente, este mesmo movimento atingiu todas as regiões do país e transformou a distribuição da população no território nacional, eliminando os desertos demográficos precedentes, como a Amazônia. É sobretudo este último movimento migratório, ligado às transformações da sociedade brasileira na segunda metade do Século XX, que chamou a atenção de Abdelmalek Sayad. Se o movimento migratório tinha tais proporções, ele provocava necessariamente nos pontos de chegada a coexistência de indivíduos oriundos de configurações sociais muito diversificadas: como, então, os migrantes originários de horizontes de partida tão diferentes reconstituíam os modos de sociabilidade e categorias de percepção do mundo social?

Assim, em 1994, estas observações e questões sobre os bairros periféricos e as favelas do Rio de Janeiro mostravam que eles constituíam-se em verdadeiros laboratórios de reconstrução do mundo social. Partindo de questões bem simples: se as favelas e os bairros periféricos possuíam a mais forte proporção de famílias de migrantes desfavorecidos, o que permite a cada recém-chegado a autorizar-se a se instalar em um lote preciso e quais são as reações dos seus vizinhos? Como as famílias justapostas por circunstâncias diversas e variadas, forçadas a coexistir e a enfrentar desafios que ultrapassavam em muito a escala doméstica, como o abastecimento de água, o destino dos resíduos, as vias de transporte, as fontes de energia etc., puderam criar laços de solidariedade e fundar o sentimento de pertencimento a algo comum, como a residência em uma localidade dotada de um nome particular? Se, obviamente, não é o Estado que controla a expansão da habitação das camadas mais desfavorecidas, nem no campo e nem na cidade, quais agentes coletivos ou reagrupamentos efetivos operam para regular algumas das questões urgentes referidas anteriormente (Igreja, clientela de políticos, traficantes [crime organizado], afinidades familiares ou geográficas etc.)?

Para Sayad, como para Pierre Bourdieu, todo coletivo, ou seja, toda coletividade, existe apenas em indivíduos de carne e osso que reconhecem sua existência; partilhar o mesmo destino é uma condição necessária, mas não suficiente para fazer um grupo existir. Uma justaposição de indivíduos e de famílias desfavorecidas em nível material e cultural se transformam em coletividade, ou em "comunidade", apenas por um trabalho realizado explicitamente com esta

12 Sobre a expansão do mercado cultural do início do Século XX, ver Miceli, 1981 e Rivron, 2005. 
finalidade. As igrejas católicas ou protestantes, se propondo a "defender a comunidade", estavam, de fato, as constituindo. E este trabalho não enfrentava somente a concorrência religiosa, mas também à de todos os outros agentes sociais que tinham interesses precisos de tornar o conjunto de indivíduos em clientes potenciais de seus serviços (como os políticos, sindicalistas e profissionais universitários - advogados, médicos, artistas etc.). O estudo sociológico da multiplicidade das ações coletivas para dotar a habitação dos migrantes instalados com poucas condições de vida associadas à urbanização (pedidos de estradas, de água e esgoto, coleta de lixo, sistema de transporte, escolas, postos de saúde etc.) tornava-se, também, um objeto incontornável para compreender a gênese e as modalidades de existência do sentimento de localidade e vizinhança. Sayad esforçou-se por objetivar a lista de questões a examinar para compreensão da existência de "patrimônios comuns" ou de serviços coletivos ausentes na ação do Estado. A entrada das populações desfavorecidas na ordem estatal, supondo o respeito dos padrões mínimos das condições de vida (direito à escolarização das crianças, eletricidade, proteção contra epidemias etc.) constituía também um objeto sociológico de primeira ordem; a extensão da cidadania ao todo da população, que fora uma questão em debate sobre a democratização do Brasil no fim do regime militar (década de 1980), significava analisar a incorporação à urbanização de contingentes recém-dotados de recursos sociais e intelectuais, abandonando uma existência submissa aos riscos da sobrevivência na urgência, para poder participar as deliberações da cidade a propósito do futuro coletivo. ${ }^{13}$ Procurar ter acesso aos serviços já disponíveis para outros domicílios urbanos é um processo propriamente político de mobilização das populações desfavorecidas, que repercute sobre a imagem do contingente que a empreende um verdadeiro processo de dignificação destes conjuntos territoriais ou destas comunidades, para empregar uma categoria "do ponto de vista nativo".

É verdade que Sayad pôde fazer uso, em 1994, da sua monografia, redigida em colaboração com Eliane Dupuy, sobre "Un Nanterre algérien, terre de bidonville" (Sayad, 1995), particularmente do questionamento sobre a relação nostálgica com o passado de sofrimentos, percebido posteriormente como marcado por uma solidariedade forte e por um sentimento de partilha de um destino

13 Todo este raciocínio se aplicava também às populações que viviam no meio rural. A pesquisa sobre os assentamentos rurais, no Rio de Janeiro e São Paulo, realizada pelo CRBC (Centre de Recherches sur le Brésil Contemporain) com muitos colaboradores brasileiros (CPDA/UFRJ [Programa de Pós-Graduação de Ciências Sociais em Desenvolvimento, Agricultura e Sociedade/ Universidade Federal Rural do Rio de Janeiro] e FEAGRI-SP [Faculdade de Engenharia Agrícola/ Universidade de Campinas]) inspirou-se também nestes questionamentos. 
difícil. Um dos seus comentários diante de uma antiga favela submissa a duas modalidades de urbanização - reconstrução de casas condizente com a reconstrução das condições de vida; construção de imóveis do gênero $\mathrm{HLM}^{14}$ para 0 realojamento dos residentes - marcou muitos espíritos: ele afirma detestar os imóveis do gênero HLM, em contraste com a urbanização lenta e progressiva das favelas. No primeiro caso - ele explicou - pessoas que nunca foram socializadas de acordo com os estilos de vida impostos pelas novas habitações (banheiros, elevadores etc.) são confrontadas a utensílios que eles dominam mal o uso; todo mal jeito provoca a degradação da habitação que funciona como uma lembrança suplementar de que eles vivem em um mundo que não é o seu. As frustrações podem causar degradações suplementares, aumentando os sinais de que eles não são feitos para estes símbolos de conforto. Ao inverso desta espiral destrutiva e autodestrutiva, a construção progressiva dos símbolos da urbanização - uma praça, uma fonte, um templo religioso, iluminação pública - pode funcionar como um certificado de novas aquisições, permitindo apropriá-las subjetivamente à medida que o patrimônio comum toma forma. A reconstrução de si produz-se, neste caso, em um ritmo que faz eco à construção de quadros de vida coletivos. Os modos de apropriação dos símbolos da modernidade são bem diferentes nas duas situações; eles colocam em questão condições de trabalho sobre si que obrigam os indivíduos a adaptarem-se na urgência ou os deixam fora dos seus movimentos. O enraizamento da vida coletiva em território novo, um objeto sociológico examinado ao longo de seu percurso acadêmico, exige que examinemos a reconstrução do quadro objetivo da vida social - prédios, instituições (igrejas, escolas, sistema de saúde, espaço político, mercados etc.), leis, aparelho judiciário - mas, igualmente, a reconstrução dos mundos subjetivos dos recém-chegados. Se eles não são subtraídos à sensação de estarem submissos a todas as urgências, dificilmente eles podem reconstruir seu mundo interior. Existe, certamente, as condições econômicas e sociais de toda reconversão bem-sucedida. Mas o trabalho sobre si é uma dimensão fundamental da reconversão, como as obras dos anos 60 tratando sobre os reagrupamentos forçados na Argélia já sublinhavam. A percepção de si e dos outros, tudo como a percepção de si para os outros, devem mudar acompanhando as transformações dos novos quadros de existência urbana. Este esforço,

14 [N. T. Habitação de aluguel moderado (Habitation à Loyer Modéré), é uma habitação administrada por um organismo de habitação de aluguel a preços abordáveis, público ou privado, que beneficia-se de um financiamento público parcial destinado às famílias com salários baixos na França]. No Brasil, estes imóveis eram conjuntos do BNH. 
incluindo necessariamente as atividades individuais, é feito, frequentemente, acompanhado de mobilizações coletivas que contribuem para o seu sucesso.

Sayad ainda chamou atenção sobre a presença constante dos elementos dotados de recursos sociais e intelectuais - militantes políticos, padres, juristas, trabalhadores da área social, estudantes, artistas etc. - que, frequentemente, eram apenas mediadores e guias que colaboravam para a implementação de movimentos associativos capazes de melhorar a qualidade de vida. A sociologia destes voluntários permite compreender os recursos que eles efetivamente possuem e também a ligação entre a oferta de seus serviços e as modalidades de concorrência no seio dos espaços profissionais de onde eles são oriundos ou figuram como aspirantes. O voluntariado frequentemente é apenas um investimento aparentemente gratuito para consolidar as condições de profissionalização posterior. ${ }^{15} \mathrm{~A}$ colocação em perspectiva sociológica deste trabalho de extensão da urbanização permite afrontar a complexidade da constituição de novas coletividades; processo, em todo caso, infinitamente menos simples que a "tomada de consciência" das condições objetivas de existência, preconizada pela linguagem encantada de diferentes tipos de discursos proféticos diante da necessidade de dar-se boas razões para aceitar o ascetismo provisório imposto pelo voluntariado e militância. A visita de postos de saúde nas periferias remotas mantidos por ONGs, escolas privadas e creches criadas pelos movimentos associativos, bibliotecas, grupos de teatro e círculos musicais, permitiram clarificar este ponto de vista. A discussão aprofundada das origens sociais, políticas e intelectuais do nacionalismo argelino autorizavam Sayad a convidar a olhar, sem nenhuma complacência, todas as formas de militância intelectual, como o fortalecimento do sentimento de localidade ou do regionalismo, detectando nelas todas as estratégias denegadas de reserva de mercado. Diante de uma biblioteca constituída somente por doações e mantida pelo trabalho voluntário, ele pede discretamente aos doutorandos do Museu Nacional: "Olhem bem os livros que estão sobre as prateleiras; digam-me depois se são os mesmos que aparecem na história da literatura brasileira e nos concursos escolares. Existem livros clássicos que vocês acham que estão faltando? Existem viés sistemáticos na presença de livros não encontrados em outros lugares?” A hegemonia das práticas culturais não encontradas em outros lugares poderia abrir o caminho para a cultura da gueto, fazendo redobrar a marginalidade dos moradores da periferia.

15 Para uma análise muito interessante das condições de existência das ONGs e do investimento dos voluntários na origem das inovações sociais, ver Hirschman, 1984. 
Uma variante do mesmo assunto, abrindo pistas preciosas para as novas pesquisas sobre o universo cultural do Brasil, foi a associação entre o retorno dos imigrantes, depois da imersão na concorrência feroz de um grande centro cultural e a criação de projetos políticos e intelectuais. A investigação conduzida atualmente no quadro do CESSP (Centre Européen de Sociologie et de Science Politique de Paris) sobre a "mobilidade internacional dos universitários e a circulação internacional das ideias", desenvolvida dentro do projeto europeu INTERCO/ SSH (International Cooperation in the Social Sciences \& Humanities), tem origem em muitas conversas desta época, especialmente visando tudo o que um investimento nacionalista devia a estes investimentos cosmopolitas precedentes, não sancionados por resultados de acordo com as expectativas (CANEDO; GARCIA JR., 2004-2005; MUNOZ; GARCIA JR., juin. 2009). Do mesmo modo, Sayad chamou atenção para a obra de patrimonialização das práticas ou dos objetos que tornavam-se os símbolos de uma "cultura" definida por sua territorialidade, cultura local, regional, étnica, nacional e mesmo folclórica, muitas vezes o fato dos antigos emigrantes que sentiam a falta, na sociedade de acolhida, de todas estas práticas que eles se propunham a fixar como atributos de um grupo social preciso e de lutar pela sua valorização (como os pratos típicos, os relatos edificantes, a música, as danças etc.). Restituir o espaço internacional da concorrência é tão importante como compreender os fundamentos sociais da negação da concorrência, pois o projeto é frequentemente apresentado apenas sob a forma da promoção de uma população, condenada ao estigma até então. Sayad estimulou, ainda, a análise sociológica dos torcedores de clubes de futebol, certamente no princípio de muitas oposições reprimidas do espaço social brasileiro em rápida transformação.

Por último, mas não menos importante, as duas estádias inscreveram-se no combate constante contra o lugar inferior da imigração na hierarquia social dos objetos de pesquisa. As migrações tendem a conhecer um lugar homólogo entre os temas dignos de merecer estudos sociológicos e ao desprezo concedido aos migrantes nas sociedades de acolhimento. Nas mãos e nas palavras de Abdelmalek Sayad, de tema menor, tratado por aqueles que dedicavam-se a "problemas sociais", muitas vezes interessados em formular projetos para "adaptar" os recém-chegados ao universo de acolhida, as migrações tornaram-se um assunto promissor que iluminou de forma privilegiada as questões da construção dos Estados nacionais, seus limites e as disputas pela hegemonia no espaço internacional. Existe uma caracterização mais precisa da atualidade desde 1990, nomeada frequentemente de uma forma pomposa como os "imperativos da mundialização", que a intensidade sem precedentes da circulação 
de capitais financeiros, ai incluído os efeitos das crises de mercado, mobilidade acompanhada em uma menor proporção pela circulação de cientistas, de intelectuais e de artistas, contrastando com todas as barreiras impostas aos migrantes desfavorecidos, haja vista os retornos forçados aos países de origem? O cosmopolitismo exibido não foi reforçado na sua posição de símbolo distintivo dos "bem dotados", em sentido oposto aos indesejados? ${ }^{16}$ Da limitação crescente à livre circulação dos indivíduos, Sayad fazia seu tema de reflexão sobre os limites do Estado nação para incorporar novas camadas sociais no espaço público; o Estado moderno, tema nobre das ciências sociais, que é apenas superado no presente pela "economia de mercado", encontra no modo de tratamento da passagem e da instalação dos migrantes sobre o território nacional um revelador de conflitos que o atravessa. Abdelmalek Sayad revalorizou a condição de migrante (emigrante/ imigrante) na prática - graças à uma escuta de uma sensibilidade e precisão raras - e na teoria.

\section{0 internacionalismo cientifico e a progressão do conhecimento universal}

Ainda mais improvável que seus percursos miraculosos, a amizade e os laços de colaboração entre Pierre Bourdieu e Abdelmalek Sayad constituem uma demonstração suplementar do caráter não determinista de sua análise sociológica. Objetivar as relações em que todo sociólogo é tomado é uma maneira de explicitar as margens de liberdade de cada indivíduo, sob a condição de não cair na complacência em relação aos próximos, nem na submissão aos pretendentes de toda espécie de poder político ou intelectual. A dedicação de Pierre Bourdieu no "Esboço de uma teoria da prática" (1983), ou no "Prefácio" do "Senso Prático" (2009), demonstra como este laço de amizade e colaboração nas pesquisas fora fundamental para abrir novas perspectivas ao pensamento sociológico, como a incorporação dos ganhos do estruturalismo e sua superação proposta pelas obras citadas, por exemplo.

A colaboração entre Pierre Bourdieu e Abdelmalek Sayad coloca em evidência igualmente as linhas de partilha entre a etnologia, que estaria dedicada ao estudo das sociedades exóticas para os Europeus e Estadunidenses, e a sociologia, circunscrita ao estudo da sociedade onde o pesquisador nasceu e foi socializado. Com a sociologia reduzida aos estudos dos próximos ou de familiares e a etnologia reduzida à análise das sociedades exóticas, cada campo científico torna-se um recinto fechado, evitando de se abrir para o outro; nós estamos

16 Anne-Catherine Wagner (2007) estuda a recomposição das classes sociais em relação com às diferentes modalidades de acesso internacional. 
em todo caso bem distantes das explicações e demonstrações que possam pretender à veracidade universal de suas proposições. Entretanto, para Sayad e Bourdieu, a colaboração iniciou-se sobre o solo argelino; ela se aprofundará na França desde os anos 60, invertendo o senso das situações de familiaridade com a sociedade e a cultura, mas permitindo aguçar o olhar fornecido pelos questionamentos originais (a análise de Bourdieu em termos de campo de poder é característico desta segunda frase) e acumulando instrumentos de pesquisa mais fortes. Se Pierre Bourdieu convidou Abdelmalek Sayad para participar da pesquisa sobre seu vilarejo natal no Bearn, retomada no Baile dos celibatários, informação confirmada por Sayad no Brasil, é, sem dúvida, porque ele acreditava que o olhar sociológico seria mais agudo se ele pudesse contar com a visão não cúmplice daquele que é oriundo de outro universo social, como a Cabília. A problemática e os métodos forjados na Argélia puderam, assim, ser postos à prova de sua universalidade, Bourdieu tomando distância a uma situação que lhe era familiar, dando oportunidade a Sayad de familiarizar-se com uma situação para ele exótica. ${ }^{17}$ Por seu lado, Sayad confirmou que o estudo das estratégias de casamento entre as linhagens Cabilas, especialmente demonstrando o caráter minoritário do casamento prescrito com os primos laterais, baseavam-se sobre sua base familiar. Ambos conheciam o universo familiar do outro e participaram diretamente das iniciativas de objetivação que lhes permitiram acessar o reconhecimento como antropólogos. Os dois fizeram carreiras como "sociólogos", reconhecidos como tal na EHESS [École des Hautes Études en Sciences Sociales], no CNRS [Centre National de la Recherche Scientifique] e no Collège de France. A busca pelo conhecimento universal sempre prevaleceu sobre o respeito das fronteiras nacionais e disciplinares.

A integração de Sayad ao Centre de Sociologie Européenne (CSE) lhe permitiu examinar os dilemas do emigrante argelino face à sociedade francesa, cujas

17 O livro citado do antropólogo Eric Wolf não faz referência às principais obras publicadas até 1964 por Pierre Bourdieu. Entretanto, ele retira de um dos seus primeiros artigos o seguinte trecho, bastante interessante como testemunho da importância da sociologia do país de origem dos migrantes para melhor identificar os conflitos na sociedade de acolhida: Bourdieu também observa que, para os argelinos, a adesão às formas tradicionais apareceram para completar "essencialmente uma função simbólica; ele representava o papel, objetivamente, de uma linguagem de recusa; e ele dá como exemplo o uso do véu, costume tradicional particularmente criticado pelos franceses: o véu usado pelas mulheres mulçumanas [...] é antes de tudo uma defesa da intimidade e uma proteção contra a intromissão. E, de modo confuso, os Europeus sempre perceberam como tal. Para o uso do véu, a mulher argelina criou uma situação de não reciprocidade; como um jogador desleal, ela vê sem ser vista e sem se deixar ser vista. E é toda a sociedade dominada que, pelo véu, recusa a reciprocidade, que vê, que olha, que penetra, sem se deixar ser vista, olhada e penetrada (Bourdieu, "Guerre et mutation sociale en Algérie" in Etudes méditerranéennes, $n^{\circ} 7,1960$, p. 27)", (WOLF, 1974, pp. 235-236). 
transformações foram examinadas cuidadosamente pelo resto da equipe, como demonstra a coleção d'Actes de la recherche en sciences sociales. A simples presença de Sayad no CSE materializa a aposta da prática das ciências sociais não limitada às fronteiras impostas politicamente. Todos os limites tornam-se susceptíveis de serem interrogados, das barreiras linguísticas às modalidades de pertencimento nacional, das fronteiras disciplinares às afinidades políticas. A reflexão sobre os vínculos entre o pesquisador e o objeto que ele escolhe faz parte necessariamente da construção do objeto da pesquisa sociológica. A universalização dos conhecimentos e das teorias adquiridas graças ao estudo da Argélia em plena mutação e da França pós-colonial não foi proposta como um postulado ou como uma evidência; ela é, em vez disto, o fruto de um trabalho específico, visando construir progressivamente um quadro de referência mais geral, permitindo compreender as configurações sociais observadas e acumulando as reflexões sobre a pertinência dos modelos explicativos precedentes. A diferença irredutível das duas trajetórias sociais e itinerários intelectuais jamais impediu o diálogo e mesmo o trabalho em comum; ela foi até mesmo o motor da universalização dos modelos explicativos, mesmo se todo conhecimento científico é percebido como provisório. Retrospectivamente, nós podemos observar que Actes de la recherche en sciences sociales fez amplamente uso do método comparativo, por justaposição de artigos que tratam sobre situações nacionais muito contrastantes, a fim de demonstrar a universalidade dos problemas tratados e as variações pertinentes das configurações sociais observáveis; esta prática em modelo reduzido verifica-se também em relação aos trabalhos de pesquisa de Bourdieu e Sayad. Sayad sempre se perguntou sobre as vias de transformação da sociedade argelina, ainda mais sobre os múltiplos destinos desta "sociedade" constituída pelos "descendentes da imigração".

As duas estadias do casal Sayad no Brasil demonstram como a reflexão sobre os ganhos de pesquisas precedentes podem ser combinados com a constituição de novos objetos de pesquisa, pela prática de um diálogo que volta sobre seus próprios pressupostos para melhor escutar o pensamento e as interrogações dos ouvintes. A universalização das problemáticas e dos instrumentos de pesquisa inscreve-se na prática do internacionalismo científico, que começa por perguntar-se sobre os recursos e os fundamentos da livre circulação de ideias e de pensadores, para melhor colocar à prova as observações e a escuta atenta dos modelos de compreensão fabricados para compreender as experiências humanas totalmente diferentes em aparência. Um migrante assumido sabe perfeitamente que todos os obstáculos à comunicação e à compreensão imediatas exige um trabalho sobre si mesmo, cuja contrapartida é o alargamento dos seus 
próprios horizontes e a construção de laços de proximidade com pessoas que carregam o traço da diferença de origem geográfica ou social. O migrante paga ele mesmo o sonho de iniciar um diálogo que o leve além de seus próprios limites; com Abdelmalek Sayad aprendemos que a deficiência de ausência de compreensão imediata pode ser a origem de um esforço para ultrapassar os limites de todo pensamento situado no tempo e no espaço. Em síntese, as viagens felizes existem.

\section{Referências}

BOURDIEU, P. Esboço de uma teoria prática. In. ORTIZ, R. (Org.) Pierre Bourdieu: Sociologia. São Paulo: Ática, 1983

O senso prático. Petrópolis: Vozes, 2009.

CANEDO, L.; GARCIA JR., A. Les boursiers brésiliens et laccès aux formations d'excellence internationale. In: Cahiers du Brésil Contemporain, $n^{\circ}$ 56/57 - 59/60, pp. 21-48, 2004-2005.

CUNHA MELLO, M. Quem explica o Brasil. Juiz de Fora: Editora da UFJF, 1999.

GARCIA JR., A. Le déracinement brésilien. In: LAGRAVE, R. M.; ENCREVE, P. (Org.), Travailler avec Bourdieu. Paris: Fayard, p. 305- 310, 2003.

. Droit, politique et espace agraire. Introduction, Etudes Rurales, $n^{\circ}$ 131-132, juillet-décembre p. 9-18, 1993.

. Fundamentos empíricos da razão antropológica: a criação do PPGAS e a seleção das espécies científicas. Mana, vol.15 nº ${ }^{2}$. Rio de Janeiro, Oct. 2009.

GARCIA-PARPET, M. F. Des outsiders dans léconomie de marché: Pierre BOURDIEU et les travaux sur l'Algérie. In : MAUGER, G. (Org.), Rencontres avec Pierre Bourdieu. Paris: Ed. du Croquant, pp. 547-564, 2005.

HIRSCHMAN, O. Getting ahead collectively: grassroots experiences in Latin America. New York: Pergamon Press, 1984.

LÉVI-STRAUSS, C. Tristes trópicos. São Paulo: Companhia das Letras, 1996. MICELI, S. Intellectuels et pouvoir au Brésil. Paris: Ed. MSH, 1981.

MUNOZ, M-C.; GARCIA JR., A. Mobilité universitaire et circulation internationale des idées. Le Brésil et la mondialisation des savoirs, Cahiers de la recherche sur l'éducation et les savoirs, hors - série ${ }^{\circ}{ }^{2}$, juin 2009.

NOIRIEL, G. A quoi sert l'identité nationale, Paris, Agone, 2007.

Population, immigration et identité nationale (XIXème - XXème siècle), Paris, Hachette, 1992 
PALMEIRA, M.; ALII. Emprego e mudança socioeconômica no Nordeste. Anuário Antropológico, 76, p. 201-238, 1978.

RIVRON, V. Enracinement de la littérature et anoblissement de la musique populaire. Paris: EHESS, thèse de doctorat (3 vol.), 2005.

SAYAD. A. Uma pobreza "exótica": a imigração argelina na França. Revista Brasileira de Ciências Sociais, $n^{\circ}$ 17, 1991.

. Imigração ou os paradoxos da alteridade. São Paulo: Edusp, 1998.

. $O$ retorno constitutivo da condição do imigrante. Travessia, Rio de Janeiro, Ano XII, 2000.

. (colab. Éliane Dupuy). Un Nanterre Algérien, Terre de Bidonvilles. Paris:

Éditions Autrement, 1995.

SIGAUD, L. Os clandestinos e os direitos. São Paulo, Duas Cidades, 1979.

. Greve nos engenhos. Rio de Janeiro, Paz e Terra, 1980.

THIESSE, A-M. La création des identités nationales: Europe (XVIIIème - XXème siècle), Paris: Seuil, 2001.

WAGNER, A-C. Les classes sociales dans la mondialisation. Paris: La Découverte, 2007. WOLF, E. Les guerres paysannes au XXème siècle. Paris: Maspero, 1974. (original americano 1969).

Recebido em 21/12/2017

Aprovado em 19/02/2018

\section{Como citar este artigo:}

GARCIA JR., Afrânio. Abdelmalek Sayad no Brasil: Os imigrantes internacionais como um caso limite de agentes sociais forçados à reconversão. Contemporânea - Revista de Sociologia da UFSCar, v. 8, n. 1, jan.- jun. 2018, pp. 59-82. 